\title{
ATUAÇÃO DO INTÉRPRETE EDUCACIONAL: PARCERIA COM PROFESSORES E AUTORIA
}

\author{
Lara Ferreira dos Santos* \\ Universidade Federal de São Carlos
}

Cristina Broglia Feitosa de Lacerda**

Universidade Federal de São Carlos

\begin{abstract}
Resumo: Este estudo visa analisar e discutir o fazer do Intérprete Educacional (IE), profissional recente no país no campo da educação de surdos e cujas pesquisas sobre sua atuação, em sala de aula, mostram-se incipientes. Nosso objetivo foi discutir, além do trabalho de interpretação de uma língua para outra (Língua Brasileira de Sinais/Português), a relação de parceria com o professor e de que forma esta pode influenciar práticas de interpretação, bem como possibilidades de criação e autoria discursiva do profissional IE. Para este propósito nos apoiamos, principalmente, nos pressupostos de Bakhtin $(2009,2010)$, e em autores da área da surdez, tradução e interpretação. Os dados selecionados para este estudo foram
\end{abstract}

\footnotetext{
* Graduada em Fonoaudiologia e Doutora em Educação Especial pela Universidade Federal de São Carlos (2014). Professora Assistente da Universidade Federal de São Carlos e Coordenadora do Curso de Bacharelado em Tradução e Interpretação em Língua Brasileira de Sinais/Língua Portuguesa, Departamento de Psicologia, na Universidade Federal de São Carlos. São Carlos, São Paulo, Brasil. E-mail: larasantos.ufscar@gmail.com

** Graduada em Fonoaudiologia, Doutora em Educação pela Universidade Estadual de Campinas (1992), com Pós-doutorado no Centro de Pesquisa Italiano - CNR ROMA (2003). Professor Adjunto II da Universidade Federal de São Carlos e Coordenadora do Programa de Pós-Graduação em Educação Especial, Departamento de Psicologia, na Universidade Federal de São Carlos. São Carlos, São Paulo, Brasil. E-mail: cbflacerda@gmail.com.
} 
coletados a partir de videogravação, e posterior transcrição, de uma aula de História com a presença de intérprete, no $6^{\circ}$. ano do Ensino Fundamental, em uma escola que se pretende inclusiva bilíngue para surdos. As análises sobre o fazer do Intérprete Educacional indicam que este não se restringe à tradução e interpretação de enunciados: ele é coautor dos discursos proferidos pelo professor em sala de aula, e sua prática se atrela ao trabalho desenvolvido pelo professor.

Palavras-chave: Intérprete Educacional. Língua Brasileira de Sinais. Tradução e interpretação de/para Libras. Surdez. Educação Especial.

\title{
PERFORMANCE OF EDUCATIONAL INTERPRETER: PARTNERSHIP WITH TEACHERS AND AUTHORSHIP
}

\begin{abstract}
This research aim to analyze and discuss the work of the Educational Interpreter (IE), which is a recent professional in our country in the field of deaf educacion, and the currently researches on their performance in the classroom are incipient. This article aimed to discuss in addition to the work of interpretation from one language to another (Brazilian Sign Language/Portuguese), their relationship of partnership with the teacher and how this may influence interpretation practices, and also the possibilities of creation and discursive authoring by professional IE. For this purpose, this research is based mostly on Bakhtinian theoretical frameworks $(2009,2010)$, and authors in the field of deafness, translation and interpretation. The data selected for this study was done in tape-recorder and subsequently transcribed, in a History classroom with the presence of interpreter, on the 6th year of elementary school that proposed be inclusive bilingual for the deaf. The analysis on the IE's performance demonstrated that the work of Educational Interpreter is not restricted to the utterances translation and interpretations: he is co-author of the discourses delivered by teachers in classroom, and your practices are connected with the teacher's practice work development.

Keywords: Educational Interpreter. Brazilian Sign Language. Translation and language interpretation to/from Libras. Deafness. Special Education
\end{abstract}

\section{Introdução}

Discutir a escolarização de surdos em nosso país reporta-nos a um período distante (algumas décadas), mas de fundamental relevância para contextualizar e compreender as atuais propostas de 
educação bilíngue. Esse caminho trilhado teve início com as discussões sobre o lugar do sujeito surdo na Educação Especial.

A partir da difusão da Lei de Diretrizes e Bases da Educação Nacional (BRASIL, 1996), estabeleceu-se que toda e qualquer pessoa com deficiência deveria ter acesso à educação, ou seja, o atendimento institucional e segregado foi, preferencialmente, substituído pelo acolhimento nas escolas regulares de ensino. A Educação Especial passou, então, a complementar o ensino nas escolas comuns, fato que se consolidou com a publicação do Decreto $\mathrm{n}^{\mathbf{0}}$ 3.298 (BRASIL, 1999).

Dessa forma, a inclusão educacional de pessoas com deficiência passou a ser defendida e divulgada como forma de garantir educação e igualdade de condições, em diversos documentos (BRASIL, 1999; BRASIL, 2000; BRASIL, 2002). Reitera-se a função da Educação Especial, desde então, junto desta clientela: a de complementar a educação regular.

A atual política nacional de educação prioriza a inserção e inclusão de todas as crianças em idade escolar em escolas regulares. Todavia, tal proposta não abarca a totalidade de atendimentos, de fato; muito ainda há que ser feito. É preciso dar garantias de permanência, igualdade de acesso aos conhecimentos e conclusão dos estudos, por meio de recursos especializados e de pessoal capacitado.

Com relação aos alunos surdos, parte significativa do público com deficiência, seu histórico de escolarização mostrou-se bastante penoso. Sabe-se que esse alunado não era bem atendido nos espaços de Educação Especial, e pouco frequentava escolas regulares. E em ambos os espaços, em geral, sequer tinha direito ao uso da língua de sinais. A proposta de inclusão mostrou-se como uma nova perspectiva frente à possibilidade de "existir", poder estar entre alunos que alcançavam as séries finais de escolarização, mesmo que a língua de sinais ainda não tivesse o devido reconhecimento. A aceitação de alunos surdos em escolas comuns, todavia, não garantiu o acesso ao currículo escolar, e tampouco aos processos de ensino-aprendizagem, visto que não eram oferecidas possibili- 
dades de desenvolvimento de linguagem e respeito por sua língua (SANTOS, 2007).

Os surdos vêm se destacando no cenário nacional, em virtude das lutas frente às políticas públicas e da busca incessante pelo reconhecimento de seus direitos linguísticos. Essa evidência deveu-se também aos recentes documentos legais publicados, que tratam da especificidade linguística e educacional desses sujeitos (BRASIL, 2002, 2005). Todo o público alvo da Educação Especial, embora necessite ainda de maior atenção e ajustes para alcançar igualdade de atendimento, utiliza e tem como língua materna o português fato que diferencia a pessoa com surdez em todo o contexto social e educacional.

Com a publicação da Lei 10.436 (BRASIL, 2002), que oficializou a Língua Brasileira de Sinais - Libras como forma de comunicação legal das comunidades surdas brasileiras, e do Decreto 5.626 (BRASIL, 2005), que determinou atribuições e o ingresso de profissionais especializados na educação de surdos, algumas mudanças passaram a ser exigidas no atendimento educacional dos surdos. Desde então, o modelo de Educação Bilíngue, proposto pelo Decreto, mostrou-se a forma mais adequada de atendimento.

A Educação Bilíngue deve contemplar as necessidades de aprendizado do aluno surdo por meio da Libras, sendo esta sua primeira língua. É somente por meio dessa língua que o surdo poderá se desenvolver de forma plena, visto tratar-se de uma língua visuogestual e que lhe possibilita o acesso aos conhecimentos, e aos aspectos culturais e identitários da comunidade surda. A partir do momento que o sujeito surdo tiver sua base linguística consolidada, ele poderá aprender a língua portuguesa, na modalidade escrita, como segunda língua (SKLIAR, 1997; LACERDA; LODI, 2009).

O texto do Decreto 5.626 (BRASIL, 2005) aponta ainda para a necessidade, na Educação Bilíngue, da presença de intérpretes de língua de sinais (ILS) ${ }^{1}$ a partir dos anos finais do ensino fundamental. Esse profissional deve ser ouvinte, e apresentar competência e fluência em Libras, possibilitando a interpretação entre esta e a língua portuguesa em instituições de ensino. Essencial na Educação 
Bilíngue, o intérprete tem sido apontado, em algumas discussões, como único profissional necessário quando da inclusão educacional de surdos. É preciso cautela e um olhar atento para a atuação do intérprete, que é parte de uma equipe de profissionais que deve figurar no espaço educacional inclusivo - mas não o único responsável pela Educação Bilíngue.

Com a publicação da Lei 12.319 (BRASIL, 2010), que regulamenta a profissão do intérprete de Libras, sua entrada no espaço escolar tornou-se mais frequente, conforme se observa em algumas pesquisas recentes (BELÉM, 2010; RODRIGUES; MIRANDA, 2012; KOTAKI; LACERDA, 2013). A criação/ existência de um cargo e a descrição de suas atribuições legais indica a necessidade desse profissional e cria condições legais para sua presença em instituições educacionais. Todavia, muito ainda há de ser feito pela Educação Bilíngue - as escolas precisam estar preparadas para receber não somente os alunos surdos, mas os profissionais também.

Para melhor compreender a participação desse profissional no processo de ensino e aprendizagem, torna-se necessária uma breve discussão sobre suas funções e demandas, o processo tradutório, as relações com outros sujeitos no espaço escolar - fatores que consideramos fundamentais à Educação Bilíngue. Serão esses os temas que abordaremos a seguir.

\section{Questões de linguagem e de interpretação}

O surgimento da prática de interpretação de/para línguas de sinais, como relata Frishberg (1990), deveu-se às dificuldades de comunicação de pessoas surdas, o que as impedia de assumir direitos e deveres como cidadãs. Com o intuito de possibilitar a comunicação entre surdos e ouvintes, membros da família, amigos próximos e vizinhos, passaram a desempenhar a função de intérpretes em situações do cotidiano, nas quais a comunicação era limitada. Essa prática, portanto, não era realizada por profissionais, o que 
acarretava em poucos cuidados com questões de compreensão dos enunciados, ética e imparcialidade (SANTOS, 2006).

Inicialmente, portanto, grande parte dos ILS atuava na esfera da interpretação comunitária. De acordo com Carr et al (1995) a interpretação comunitária visa à comunicação entre usuários e não usuários de uma língua, e culmina em trabalhos desenvolvidos nos diversos espaços sociais, tais como saúde e educação.

[...] as atividades de tradução e interpretação sempre foram exercidas por indivíduos na função de mediadores em interações em que a barreira lingüística impediria a comunicação, seja de textos escritos ou textos orais, no contexto de uma prática oficiosa. Com o passar do tempo, esses tradutores e/ou intérpretes se transformaram no profissional 'tradutor/ intérprete' e as artes da tradução/interpretação foram, lentamente, consolidando-se como um conjunto de competências passíveis de ensino/aprendizagem, passando a constituir o ramo aplicado do campo disciplinar hoje conhecido como Estudos da Tradução. (VASCONCELLOS, 2010, p. 123).

Por se tratar, portanto, de uma área de pesquisas recente e cujos cursos de formação ainda não haviam se consolidado, por muitos anos as pesquisas sobre interpretação em língua de sinais estiveram bastante distantes dos Estudos da Tradução - a aproximação deu-se nas últimas décadas. Vasconcellos (2010) aponta que pesquisas no campo da língua de sinais, nos dias atuais, vêm conquistando maior credibilidade em virtude dessa filiação; muito se tem discutido sobre possíveis campos de atuação (para além da esfera comunitária) e formação.

O contexto educacional é um desses espaços que tem se destacado no campo da interpretação de língua de sinais. Alunos surdos frequentam salas de aula regulares e necessitam de respeito por sua condição linguística diferenciada; a presença do intérprete nas escolas é indispensável, pois é ele quem vai possibilitar o acesso às informações e conteúdos ministrados ao aluno surdo - mais que 
isso, esse profissional é o elo de sedimentação na construção de sentidos e conhecimentos.

Compreendemos o ato de interpretação de/para Libras como uma atividade social, uma prática discursiva concreta, e não como um conjunto de técnicas linguísticas embasado na busca por sinais e palavras equivalentes entre línguas. É necessário compreender que a língua é um sistema em constante movimento, em que há significados mais ou menos estáveis, é claro, mas que para além deles é preciso se apropriar dos sentidos, das entrelinhas, do querer dizer - e isso só é possível em situações de uso da língua. “'Dizer' é algo que usa sinais ou palavras porém é bem mais do que apenas usar sinais ou palavras, é entrar na dimensão do sentido, no evento de construção do sentido" (SOBRAL, 2008, p. 131).

A função de tornar acessível o que era incompreensível, tornando os discursos inteligíveis ao interlocutor surdo (e vice-versa) é a maior responsabilidade do intérprete de língua de sinais (ILS) - e também do Intérprete Educacional (IE). É sabido que muitos surdos têm acesso tardio à língua de sinais, o que acarreta em prejuízos para a linguagem e constituição do sujeito (GURGEL, 2004). Ao se deparar com um público surdo que pouco conhece a língua de sinais, ou mesmo a temática do discurso a ser interpretado, o cuidado com a interpretação deve ser ainda maior. O profissional deve estar atento à compreensão de seu interlocutor, deve se aproximar da realidade dele, naquele momento, visando seu completo acesso à informação - não significa que o ILS/IE deva inferiorizar o surdo ou explicá-lo como se fosse incapaz, mas adequar-se àquele contexto, conforme expõe Sobral (2008, p.132):

Assim, o intérprete tem de ser um profissional capaz de entender quando deve dizer o que a quem e de que maneira, a depender de onde ele esteja e quem esteja envolvido. Daí minha afirmação de que interpretar em Libras também é dizer o "mesmo" a outros, ou seja, dizer uma coisa de acordo com a situação em que se diz, com a intenção de quem diz e com as características daquele a quem se diz. 
Para Bakhtin (2010) a principal característica do enunciado é seu direcionamento a alguém; diferentemente das palavras e orações, que são imparciais e não pertencem a ninguém, os enunciados têm "dono", são produzidos por alguém e endereçados a alguém. Nesse processo de construção do enunciado, sempre se considera seu interlocutor, esse outro que influencia profundamente sobre o enunciado; a fala é determinada pelas concepções, convicções, crenças, valores e ideais do interlocutor, pois ao enunciar espera-se a compreensão responsiva do outro.

$\mathrm{Na}$ tradução e interpretação de Libras esse processo ocorre em dois momentos: na construção do enunciado pelo falante (que tem como interlocutores sujeitos surdos, ouvintes e o ILS/IE) e na reconstrução desse enunciado para o público surdo. Consideramos, então, esse processo de extrema complexidade, exigindo do profissional percepção e flexibilidade na reprodução/recriação dos enunciados. Para atuar dessa forma é preciso que o profissional tenha, além dos aspectos relacionados, uma boa percepção dos outros que participam dessa enunciação. E, principalmente, é preciso ética, a fim de identificar as necessidades de seu interlocutor; e ter uma conduta responsável diante do locutor também não significa melhorar ou complementar a mensagem enunciada, mas adequá-la ao seu público.

Com relação ao trabalho em sala de aula, ressalta-se que este envolve linguagem, escolhas por parte do IE, reflexão, relações sociais com diferentes sujeitos, e participação no processo de ensino e aprendizagem. Para além da tarefa de transposição de uma língua à outra, a atuação do IE abarca a construção de enunciados e sentidos presentes na mensagem enunciada pelo(s) (muitos) outro(s), respeitando-se os conteúdos e gêneros discursivos em questão, além de abranger diversas áreas de conhecimento. Consideramos, portanto, que o intérprete é o profissional que atua na fronteira de sentidos da língua de origem e da língua alvo, apropriando-se dos sentidos do discurso do outro, sem prender-se à sua forma linguística, realizando as traduções de forma a garantir a completude da mensagem nesta nova produção (LODI; ALMEIDA, 2010). 
Além da complexidade natural que permeia os processos de interpretação, soma-se a esse fator o espaço em que isso ocorre: a escola e, mais especificamente, a sala de aula. Neste espaço se dá a formação de conceitos pelo aluno surdo. De acordo com Vigotski (2008, p.104): o processo de formação de conceitos é um ato de extrema complexidade do pensamento, que não pode ser simplesmente transmitido ou ensinado por meio de treinamento; "em qualquer idade, um conceito expresso por uma palavra representa um ato de generalização". E, destaca-se que, os conceitos, ao longo do tempo, se transformarão à medida que o intelecto se desenvolve, ganhando novas significações, tornando-se outra generalização de tipo mais refinado, formando os verdadeiros conceitos científicos.

Pensemos então na criança surda inserida em um contexto inclusivo. Dificilmente a criança poderá desenvolver uma teia de conceitos se ela nem mesmo domina uma língua; a forma como ela se apropria de palavras e conceitos depende da língua utilizada para este fim, e a língua utilizada pelo professor para ensinar não é acessível a ela. E, mesmo se houver presença de intérpretes, os conceitos científicos serão interpretados de uma para outra língua - e, como se sabe, todo processo de transição de uma para outra língua sofre perdas (ECO, 2007).

Quando um adolescente surdo chega à segunda etapa do Ensino Fundamental, muitas vezes com conhecimentos precários da Libras, tem de lidar com a presença do IE, de diferentes professores que não se comunicam com ele, e com uma infinidade de novos conceitos de áreas diversas. Para o aluno surdo, elaborar conceitos nesse contexto torna-se tarefa complexa; para o IE, traduzir e interpretar tais conceitos é algo extremamente delicado. Por isso, ressalta-se a importância de o professor responsabilizar-se por seu aluno surdo, afinal é ele quem domina os conceitos científicos e as estratégias de ensino para possibilitar a internalização pelo aluno.

Além de mediador entre professores e alunos surdos, e alunos surdos e alunos ouvintes - e mediador do conhecimento -, o IE atua em um ambiente onde prevalecem as relações de poder, em que a língua majoritária (o português) determina as atividades a 
serem realizadas, um espaço de muitas vozes e embates. Nesse contexto o intérprete precisa, portanto, estabelecer parceria com o professor, e também com o aluno, sem que tais relações demarquem uma postura favorável a um ou outro.

O professor é responsável pelo ensino, por proporcionar o conhecimento científico ao aluno, e o IE é responsável por transformar a informação de uma para outra língua. Quando da presença do aluno surdo, ambos são imprescindíveis: o professor precisa do IE para lhe auxiliar nas questões da surdez e da Libras (que ele desconhece), e o IE necessita da boa atuação e conhecimento do professor para que seu trabalho seja efetivo.

Apenas a presença do IE não garante a inclusão do aluno surdo; é preciso que as práticas em sala de aula sejam revistas, de forma a atender as necessidades do aluno. Se a escola não atentar para a metodologia utilizada e para o currículo proposto, as práticas acadêmicas podem ser bastante inacessíveis ao aluno surdo, apesar da presença do intérprete (LACERDA; POLETTI, 2009). O intérprete, além de apresentar fluência nas línguas envolvidas no processo tradutório, frequentemente é alguém envolvido com as comunidades surdas, com inúmeros conhecimentos sobre as dificuldades do cotidiano, as formas de compreensão, e estratégias comunicativas para com esses sujeitos.

Lacerda, Santos e Caetano (2013), abordam questões referentes à metodologia de ensino para alunos surdos e levantam alguns aspectos de extrema relevância, e que merecem maior atenção. Um dos aspectos levantados pelas autoras é a importância do acesso anterior ao conteúdo pelo IE, o que pode facilitar sua atuação; isso pode ser propiciado nos momentos de planejamento do professor. Embora possa parecer que esse momento seja exclusivamente do professor, já que é ele quem seleciona o que e como ensinar em sala de aula (e de acordo com o projeto político pedagógico da escola), o IE pode contribuir e muito para um planejamento adequado no contexto inclusivo.

Além do acesso ao planejamento, faz-se necessária a participação do IE nesse processo - não de forma a interferir na escolha 
do que será ensinado, mas no sentido de promover uma reflexão conjunta, que pode determinar metodologias e estratégias mais adequadas ao trabalho em sala de aula. Afinal, o intérprete, como conhecedor das questões da surdez, pode oferecer ideias, sugestões e desenvolver materiais visuais para auxiliar o professor - e que favorecerão a todos os alunos.

Mais que dividir tarefas e definir funções e papéis, no contexto da inclusão escolar faz-se necessário somar: unir conhecimentos em prol do desenvolvimento do aluno, fazer parte do todo escolar como parceiros profissionais, atuar em consonância de ideias. Embora as relações sociais no espaço escolar não sejam amenas e haja, de fato, uma hierarquia, é preciso que professor e intérprete caminhem lado a lado, afinal, para que ambos possam atuar da melhor forma possível, é preciso cooperação e reciprocidade. Quando se pensa em educação bilíngue de surdos, no contexto inclusivo, um não existe sem o outro ${ }^{2}$.

Essa parceria, vital, pode proporcionar ao IE maior liberdade no momento da interpretação; uma vez que a relação seja constante e de confiança, o profissional sente-se mais seguro com relação aos conceitos, permitindo-se criar e recriar os enunciados de formas mais elaboradas. Remetemo-nos aqui ao conceito de transcriação, desenvolvido por Haroldo de Campos (2013). Campos anunciava a recriação como transformação do texto original (referindo-se à tradução de poemas, mais especificamente), pois a função da tradução seria, sob seu ponto de vista, uma recriação da forma do poema em outra língua, mantendo-se a trama e os sentidos - e não visando recuperar os significados de uma para outra língua. A ideia era criar, de forma análoga, outro texto na língua alvo, mantendo seus elementos e características principais a fim de causar no leitor o mesmo impacto que o texto original causaria (TÁPIA; NÓBREGA, 2013).

Embora este conceito esteja voltado para a tradução de poemas, e para a escrita especificamente, nota-se que pode ser pensado para todo o tipo de tradução e de interpretação. Afinal, o princípio fundamental desse processo não é manter a mensagem original? Os caminhos para a realização da tradução ou da interpretação podem 
ser múltiplos, mas importa que os sentidos pretendidos sejam os mesmos na língua de chegada.

Pode-se compreender a transcriação como aquilo que excede à tradução e/ou interpretação, os limites das línguas, com o intuito de compensar as perdas ocorridas durante esse processo. Seria a transformação da informação original (em um sistema semiótico), em outro texto, também original e autônomo (em outro sistema semiótico), visto que é permitido ao tradutor e ao intérprete certa "interferência" no conteúdo. Essa conceituação confere vida ao profissional, que tem participação ativa no processo - e não mais se mantém a sombra do autor -, pois a nova criação assume o lugar do texto que a originou dando-lhe novas vestimentas, mas mantendo sua essência (BIAGGI, 2007).

Qualquer pessoa, ao realizar um discurso, seja ele próprio ou traduzido, o faz a partir de enunciados próprios e alheios. Trata-se de um processo de assimilação da palavra dos outros, que envolve certo grau de criação, percepção, valor, expressão, reelaboração e, por fim, uma produção - não de palavras da língua, mas reflexo das muitas vozes que cada palavra carrega em si (BAKHTIN, 2010). A interpretação não escapa a esse princípio, visto que o discurso emitido e o discurso interpretado são palavras próprias e alheias ao profissional intérprete, num emaranhado de sentidos que se produz em um tempo presente, concreto.

É a partir deste olhar teórico que pensamos a atuação do IE em sala de aula. Refletir sobre as relações e escolhas deste profissional - em um espaço bilíngue, com todas as tensões entre os indivíduos e em meio a construção de conceitos pelo aluno surdos - mostra-se nosso objeto de estudo.

\section{Contexto metodológico \\ O Programa Escolar Inclusivo e Bilíngue}

A presente pesquisa ${ }^{3}$ foi realizada em um espaço privilegiado, considerando as experiências atuais de educação bilíngue para sur- 
dos e as oportunidades de atuação de IE. Apresentaremos o contexto onde se deu o presente estudo, bem como as condições de atuação do profissional IE, a fim de proporcionar melhor compreensão sobre o todo do processo.

$\mathrm{Na}$ escola onde os dados foram coletados estava em andamento um Programa Escolar Inclusivo e Bilíngue, desenvolvido em um município de grande porte do estado de São Paulo desde o ano de 2009, tendo como proposta a preparação de escolas polo para o atendimento de alunos surdos, visando à adequação de práticas pedagógicas, acessibilidade e permanência destes nas escolas. E também a formação/capacitação de profissionais para atuação de acordo com uma proposta de inclusão escolar bilíngue - em atendimento ao Decreto 5.626 (BRASIL, 2005). A partir de uma parceria entre Rede Municipal de Educação e pesquisadores de universidades, foi possível desenvolver o Programa em diversas escolas, da Educação Infantil à Educação de Jovens e Adultos.

$\mathrm{Na}$ Educação Infantil e nos anos iniciais do Ensino Fundamental eram oferecidas "Salas Libras língua de instrução"; dessa forma pode-se equiparar o ensino de alunos ouvintes e surdos, oferecendo aos alunos surdos a oportunidade de aprender os conteúdos escolares em sua língua. O professor regente era bilíngue, ou seja, proficiente no uso da Libras e da língua portuguesa, e contava com a parceria da coordenação da escola e demais professores. Eram realizadas discussões frequentes sobre estratégias pedagógicas mais adequadas aos alunos surdos e os conteúdos a serem ministrados, que deveriam ser os mesmos que aqueles oferecidos aos alunos ouvintes. Dessa forma, foi possível proporcionar ensino e aprendizagem em condições de equidade a todos os alunos, e ainda promover atividades que possibilitaram a aproximação entre surdos e ouvintes.

Nos anos finais do Ensino Fundamental e Educação de Jovens e Adultos os alunos surdos eram inseridos em salas de aula com os demais alunos e sua inclusão era mediada por IE, de maneira a terem acesso às propostas e conteúdos desenvolvidos pelos professores das diferentes áreas de conhecimento, de acordo com as diretrizes e parâmetros curriculares para cada ano. 
Aos alunos surdos - em todas as etapas - foi oferecida a oportunidade de aprendizagem da língua de sinais, considerando-se que boa parte das crianças e adolescentes surdos não têm acesso precoce a esta, e que a maioria deles, conforme cita Moura (2000), é filho de pais ouvintes. As Oficinas de Libras ${ }^{4}$ se constituíram como espaço destinado aos alunos surdos e tinham o objetivo de propiciar o desenvolvimento linguístico dos mesmos, sendo ministradas por um instrutor surdo ${ }^{5}$. Nesse espaço a Libras era desenvolvida de maneira mais natural, lúdica, objetivando a imersão dos alunos no universo da linguagem e da língua de sinais.

Além do ensino da Libras, língua através da qual os surdos têm acesso a todas as informações presentes no espaço escolar, nesse espaço pode-se abordar questões relacionadas à identidade e aspectos culturais, já que o instrutor surdo é um adulto representante dessa comunidade - modelo para os alunos. Essas Oficinas eram parte da grade curricular dos alunos surdos. Eram oferecidas Oficinas de Libras também para os professores e funcionários, visando à circulação da língua em todos os espaços, e permitindo a comunicação com iguais e diferentes. E ainda aulas de Libras para os alunos ouvintes, com o mesmo intuito - para estes a Libras era parte da matriz curricular, sendo uma disciplina ministrada por professor bilíngue (acompanhado pelo instrutor surdo) ${ }^{6}$, oferecida semanalmente, para viabilizar os processos comunicativos no espaço escolar ${ }^{7}$.

Vale ressaltar ainda que, diferente de muitas experiências de inclusão, em que se observa a presença de um único aluno surdo por classe ou escola, a proposta desse Programa foi criar um ambiente com igualdade de condições e oportunidades a esse aluno, ou seja, oferecer experiências de semelhança e diferença, com a presença de vários usuários de Libras em uma mesma classe.

Considerando a especificidade do ensino de português para surdos, o qual deve ser ministrado como segunda língua (BRASIL, 2005) e, portanto, separadamente dos alunos ouvintes, eram ministradas aulas de português nos anos finais do Ensino Fundamental e Educação de Jovens e Adultos. Estas eram conduzidas por professor bilíngue (em muitos momentos acompanhado pelo instrutor 
surdo) e preparadas de acordo com as necessidades do grupo, sempre assumindo a Libras como língua de instrução. Na Educação Infantil e nos anos iniciais do Ensino Fundamental o português era ministrado pelo próprio professor regente bilíngue.

\section{Contexto de atuação do Intérprete Educacional e delinea- mento metodológico}

O foco do presente estudo deu-se em uma escola de Ensino Fundamental que contou com a presença de professores bilíngues (para atuação nos anos iniciais em salas língua de instrução Libras, e nas aulas de português como segunda língua nos anos finais), instrutores surdos (para ensino da Libras para alunos surdos, ouvintes e profissionais da escola) e IE (para atuação nos anos finais).

Além da inserção desses profissionais, a escola contou com assessoria constante dos pesquisadores, visando um processo de capacitação contínua dos profissionais envolvidos. Neste contexto, os intérpretes participavam das reuniões de planejamento das aulas junto aos professores, portanto, podiam esclarecer suas dúvidas, dar sugestões, e ter um preparo anterior à aula. Tais práticas culminaram em uma atuação mais positiva por parte dos intérpretes.

Esta escola contava com a presença de seis IE; sua carga horária era de vinte e quatro horas semanais, distribuídas entre o trabalho em sala de aula, algum tempo disponível para estudo e troca de experiência com os demais colegas, e ainda participação nas reuniões de planejamento com professores, semanalmente.

A formação dos IE era variada; apenas um deles não apresentava formação em nível superior. Todos apresentavam experiências anteriores de interpretação, especialmente em ambientes religiosos - e nenhum deles havia atuado anteriormente como IE nesta etapa da educação.

Vale ressaltar que participaram da pesquisa, já que se trata de um estudo maior (conforme referido anteriormente), além dos IE, três professores, de diferentes áreas do conhecimento - para uma 
maior abrangência dos saberes -, referidos como bons professores pela equipe escolar. Para este recorte, observou-se uma intérprete atuando na disciplina de História. Selecionamos este episódio (de um banco de dados) pois apresenta um momento rico de elaboração conceitual pelo IE que, pela parceria com o professor, seus conhecimentos e percepção da necessidade dos alunos, conseguiu realizar a interpretação de maneira satisfatória. Além disso, possibilita a compreensão da relação entre intérprete e professor - e de como esta relação influencia na atuação do IE -, e conta com um momento de criação/autoria do IE a partir dos enunciados do professor. O referido episódio foi videogravado ${ }^{8}$ no segundo semestre de 2011 e possibilitou a observação da realidade - as interações e as práticas -, possibilitando uma visão ampla dos processos e dos produtos sociais nesse espaço.

A dinâmica das aulas de História consistia não apenas na exposição de determinado tema, mas de diálogo e interação constante com os alunos, questionando seus conhecimentos, retomando discussões de aulas anteriores, em um processo de construção coletiva dos conhecimentos, por meio da interação dialógica. Além disso, a professora fez uso, em todas as aulas observadas, de recursos pedagógicos que apoiavam seus enunciados, quer por meio de imagens e cartazes, quer pela apresentação de vídeos ou leitura de textos. Algumas características dessas aulas se mostraram positivas e favoráveis à prática do $\mathrm{IE}$, e por isso serão salientadas ${ }^{9}$.

O episódio foi transcrito de forma que o leitor pudesse acompanhar cada uma das enunciações, e apresentado em quadros, nos quais os eventos foram expostos simultaneamente, a fim de facilitar a leitura.

O discurso oral, produzido por professores, alunos ouvintes e intérpretes de Libras (quando da interpretação para o português oral) foi transcrito para o português. Os enunciados produzidos pelos intérpretes educacionais foram transcritos para Libras, e baseados nos procedimentos de notação de Lodi (2004), com algumas alterações que visaram facilitar a compreensão do leitor ${ }^{10}$. Esses enunciados apresentam-se na mesma linha de seu interlocutor, uma 
vez que produzidos em simultaneidade, e estão divididos por linha pontilhada.

Abaixo as principais formas de transcrição adotadas para a apresentação dos dados:

\begin{tabular}{|l|l|}
\hline EVENTO & NOTAÇÃO \\
\hline Enunciados em Libras & $\begin{array}{l}\text { Transcrição para Libras - em letra } \\
\text { maiúscula (LODI, 2004) }\end{array}$ \\
\hline Enunciados simultâneos & Linha pontilhada \\
\hline Enunciados orais & Português corrente \\
\hline $\begin{array}{l}\text { Observações sobre locutores: } \\
\text { Professores, alunos ouvintes e } \\
\text { surdos }\end{array}$ & $\begin{array}{l}\text { Português corrente - entre } \\
\text { parênteses e em itálico }\end{array}$ \\
\hline $\begin{array}{l}\text { Marcação em azul } \\
\text { Trechos em que a apresentação de } \\
\text { imagens da interpretação se fez } \\
\text { necessária }\end{array}$ \\
\hline $\begin{array}{l}\text { Gestos e ações não verbais } \\
\text { associadas ao IE }\end{array}$ & $\begin{array}{l}\text { Em português corrente - entre } \\
\text { parênteses. }\end{array}$ \\
\hline
\end{tabular}

As discussões foram amparadas nos pressupostos da perspectiva enunciativa discursiva, proposta por Bakhtin (2009, 2010), visto que oferece a possibilidade de compreensão da relação dialógica vivenciada pelo IE - e também na literatura da área de linguística, tradução e educação de surdos.

\section{Resultados e discussão}

Para este estudo selecionamos um episódio que possibilita melhor compreensão das relações entre intérprete e professor - e de como esta relação influencia na atuação do IE -, e também de um momento de criação e autoria do IE a partir dos enunciados do professor. 
O episódio a seguir ocorreu em uma aula de História; tratava-se de uma sala de $6^{\circ}$ ano, com 25 alunos ouvintes, 4 alunos surdos e com a presença de intérprete. A professora, nessa aula, deu continuidade a um tema anteriormente trabalhado junto aos alunos, História Antiga e Mesopotâmia. Nas aulas anteriores ela havia mostrado um vídeo, cartazes com imagens do referido período e mapas. Nesta aula abordou o problema das cheias constantes que aconteciam naquele momento da história. As chuvas causavam transtornos à sociedade, devido à proximidade das construções de casas às margens dos rios, que transbordavam e destruíam as construções ao seu redor. Ela, então, explana com os alunos que medidas foram tomadas para superar o problema das cheias, fazendo uso de relatos e relembrando aulas anteriores.

\begin{tabular}{|c|c|}
\hline $\begin{array}{l}\text { Enun- } \\
\text { ciado }\end{array}$ & Locutores \\
\hline \multirow[t]{2}{*}{1} & $\begin{array}{l}\text { Professora: ... Como que eu vou poder lidar com este } \\
\text { período de chuva, com este período de cheia, da cheia do } \\
\text { rio que alaga ao redor e proximidades, das aldeias que } \\
\text { estão ao redor do rio? }\end{array}$ \\
\hline & $\begin{array}{l}\text { IE: COMO CHUVA AGUA ENCHENTE, COMO } \\
\text { EVITAR PROBLEMA COMO? COMO AGUA- } \\
\text { TRANSBORDAR-AO-REDOR? }\end{array}$ \\
\hline \multirow[t]{2}{*}{2} & $\begin{array}{l}\text { Professora: Aí o vídeo nos mostra que um dos principais } \\
\text { [...] descobertas deles vão ser os canais de irrigação. O } \\
\text { que que vão ser os canais de irrigação? }\end{array}$ \\
\hline & $\begin{array}{l}\text { IE: LÁ VÍDEO-ABRIR MOSTRAR, ANTES PRINCIPAL } \\
\text { PRIMEIRA-VEZ DESCOBRIR O-QUE? ACONTECER } \\
\text { AGRICULTURA CAMINHO CAVAR-COM-A- } \\
\text { MÃO CAVAR-COM-A-MÃO CAVAR-COM-A-MÃO } \\
\text { CAMINHO, SIGNIFICAR O-QUE? }\end{array}$ \\
\hline
\end{tabular}




\begin{tabular}{|c|c|}
\hline & \\
\hline \multirow[t]{2}{*}{3} & $\begin{array}{l}\text { Professora: A professora não é muito boa de desenho, mas } \\
\text { eu vou tentar fazer com que vocês tentem imaginar aqui, } \\
\text { oh... }\end{array}$ \\
\hline & $\begin{array}{l}\text { IE: EU DESENHO ÓTIMO NÃO, MAS TENTAR } \\
\text { MOSTRAR VOCÊS CLARO ENTENDER, PENSAR } \\
\text { ENTENDER... }\end{array}$ \\
\hline \multicolumn{2}{|c|}{$\begin{array}{l}\text { Neste momento a professora faz comentários sobre o vídeo, com } \\
\text { relação aos telhados das casas, construções e outras observações; } \\
\text { e também sobre a distância das casas do leito do rio, para evitar as } \\
\text { cheias, o que causa um problema, pois a distância da água dificulta } \\
\text { a agricultura. Então retoma seu discurso apontando as soluções } \\
\text { possíveis. }\end{array}$} \\
\hline \multirow[t]{2}{*}{4} & $\begin{array}{l}\text { Professora: Eu posso sim fazer a construção mais longe do } \\
\text { rio, desde que eu consiga levar a água até onde eu preciso, } \\
\text { tá? Então eu passo a ter a construção mais distante. }\end{array}$ \\
\hline & $\begin{array}{l}\text { IE: PODER CONSTRUIR CASA LONGE MAS ÁGUA } \\
\text { CANAL-LEVAR AGRICULTURA CANAL-LEVAR. } \\
\text { CONSTRUIR CASA COMEÇAR LONGE. }\end{array}$ \\
\hline \multirow[t]{2}{*}{5} & $\begin{array}{l}\text { Professora: Mas até que deu pra perceber pelo vídeo } \\
\text { que ela é bem próxima à margem do rio ainda, mas eu } \\
\text { faço pequenos canaizinhos por onde a água vai conseguir } \\
\text { circular e essa água vai me levar até onde eu preciso, onde } \\
\text { eu desejo. Isso, um caminhozinho. }\end{array}$ \\
\hline & $\begin{array}{l}\text { IE: MAS VÍDEO VER PERTO AGUA RIO PERTO, } \\
\text { MAS PERTO POSSIVEL MAS (aponta para o desenho } \\
\text { na lousa) CAVAR-COM-PÁ CANAL-LEVAR. AGUA } \\
\text { CASA CANAL-LEVAR AGUA-DESCER. CAMINHO. } \\
\text { EXEMPLO. }\end{array}$ \\
\hline
\end{tabular}




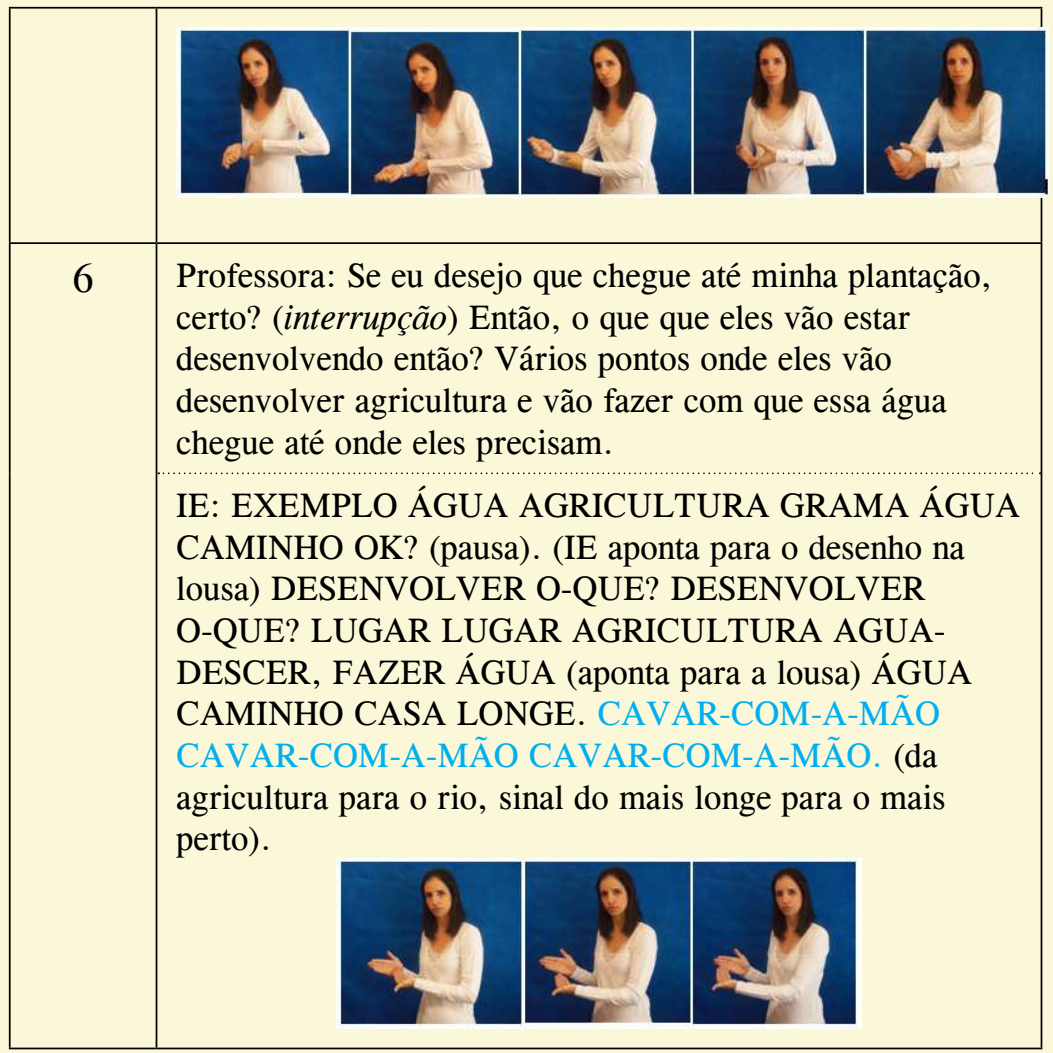

Neste trecho a IE acompanha a construção conceitual e o raciocínio desenvolvidos pela professora de forma totalmente imersa na língua de sinais. Ela busca os sentidos no contexto amplo, baseada na narração da professora, em seu desenho e no vídeo anteriormente apresentado: a interpretação se dá de forma simultânea e nota-se que a IE não perde o sentido do que é enunciado pela professora.

Nota-se, no momento da enunciação, que não há um correspondente imediato na Libras para o termo "canais de irrigação", mas a forma como a professora conduz a explicação, leva a IE a construir, literalmente, o sinal em uso - nas imagens é possível 
perceber que ela não cria um sinal para o termo, mas 'constrói os canais, ao cavar a terra e fazer o caminho que levará a água até o local desejado' com seus gestos, que vão ganhando valor de signos. Talvez esse seja o motivo do uso hesitante ao longo da interpretação dos 'sinais': CAVAR-COM-A-MÃO e CAVAR-COM-A-PÁ. A formulação da enunciação pela IE consistiu em dar sentido à completude do processo enunciativo-discursivo da professora, sem que houvesse uma preocupação com determinar/nomear os canais de irrigação, mas com o compromisso em desenvolver o conceito em questão.

Com base na teoria enunciativa discursiva proposta por Bakhtin (2010), compreendemos que o intérprete vivencia um processo complexo, simultâneo, real e concreto, em que busca nos conhecimentos de mundo e línguas a melhor forma de significar os enunciados ditos e pretendidos.

Há criação por parte da IE a todo o momento, assim como o uso de inúmeros classificadores ${ }^{11}$, que são parte indispensável da língua e do processo de interpretação. Porém, nota-se que quando o IE tem habilidade e traquejo para circular entre os discursos nas duas línguas - Libras e Língua Portuguesa - essa criação não requer estratégias ou recursos especiais - externos a língua. O próprio contexto, o uso dos gestos/sinais, leva à compreensão. Não se trata de uma criação a esmo ou de uma estratégia específica (no sentido de técnica) de interpretação, mas de compreensão do sentido pretendido e de promover condições para que tal sentido aconteça também na língua de sinais.

A criação, portanto, refere-se mais a autonomia do profissional em transcriar os enunciados e torná-los acessíveis e compreensíveis, que desenvolver novos termos. É esta autonomia que confere ao profissional uma posição diferenciada quanto ao discurso, a posição de autor, possibilitada também pelo contexto educacional.

Martins (2013) discute em sua pesquisa a posição-mestre assumida pelo intérprete e sua estreita relação de ensino quando da atuação em sala de aula. A autora defende que o profissional não é mero transmissor de uma língua a outra, mas que cria de forma 
ativa, e interfere no discurso do outro, durante todo o processo de interpretação. Ao abordar os requisitos éticos necessários à atuação do intérprete, tais como imparcialidade, distância profissional e fidelidade, a autora aponta para a impossibilidade de atuar dessa forma em sala de aula, visto que o contato diário com o aluno e o acompanhamento dos processos de aprendizagem por um longo período jamais se mostram neutros, imparciais - afinal o IE demonstra maior conhecimento e aproximação com o aluno surdo que o próprio professor. "[...] e aqui é minha aposta, caracteriza uma posição ativa de um sujeito que se envolve com o processo de aprendizagem do outro e possibilita o que sente ser importante para impulsionar o aprender (MARTINS, 2013, p. 129)".

Além do desempenho do IE nesse episódio é necessário destacar que tal atuação, carregada de sentidos e ajustada ao discurso oral, deve-se também à atuação adequada da professora. Ela demonstra uma preocupação genuína com o aprendizado dos alunos, ao planejar sua aula com cautela, de forma a proporcionar a compreensão a todos os presentes - alunos ouvintes, alunos surdos e intérprete. Um único tema é trabalhado por meio de vídeo, desenhos na lousa, explicações detalhadas e exemplificadas, com a discussão/participação dos alunos na construção dos conhecimentos - possibilitando ao IE tecer um texto coerente, para que os alunos surdos tenham acesso ao que é exposto em condição de igualdade com os alunos ouvintes. A professora em questão demonstra uma postura diferenciada ao adequar suas aulas visualmente, e ao retomar/revisar discussões anteriores com os alunos, e, por conseguinte, auxilia o intérprete em sua atuação.

Se o professor não assumir práticas que favoreçam a atuação do ILS, consequentemente a compreensão do aluno surdo ficará comprometida.

Para desenvolver práticas acadêmicas acessíveis, é necessário, antes de qualquer adaptação curricular, que haja parceria entre professor e ILS. (LACERDA; SANTOS; CAETANO, 2013, p. 196). 


\section{Considerações finais}

Discutir o fazer do IE mostrou-se um trabalho intenso, denso e carregado de novos questionamentos. A observação de sua prática em sala de aula, lidando com as mais diversas ocorrências e contextos, levou-nos a algumas reflexões sobre o que é desejável e o que é possível nesse contexto ${ }^{12}$.

Está claro que uma grande parcela do fazer do IE é influenciada pelas práticas pedagógicas assumidas pelos professores que o cercam - mais que influenciada, é impregnada. A didática escolhida pelo professor influencia as opções linguísticas e semióticas do profissional. A aula pode assumir característica mais expositiva, dialogada ou prática, mas o que mais importa é o fato de o professor ter um compromisso com o ensino para todos, preparando sua aula de forma a possibilitar a compreensão, e o acesso ao conhecimento científico proposto. Quando isso ocorre o intérprete também é beneficiado, pois pode se preparar/estudar com antecedência e, ainda, contar com recursos que lhe deem apoio no momento da interpretação - imagens, vídeos, cartazes e a própria lousa. O IE, quando inserido em salas de aula com didática diferenciada tem maior liberdade na interpretação, permitindo-se criar e construir sentidos de forma mais aprofundada, mais envolvida pelos/com os conceitos.

Constatamos que o fazer do IE não se restringe à interpretação de enunciados, sua prática cotidiana vai além desse aspecto; o IE é coautor dos discursos proferidos pelo professor em sala de aula. Partimos do pressuposto que o contexto da sala de aula é tão complexo que os dizeres do professor seriam "intraduzíveis", não pela questão linguística ou pela forma de apresentação dos mesmos, mas pelos muitos elementos presentes nessa conjuntura.

O intérprete realiza a apreensão do enunciado, destrincha-o em conceitos, apropriando-se de seus sentidos e detalhes mais profundos, reorganiza-o mentalmente, traz a língua de chegada para dialogar com todos esses aspectos e, só então, enuncia novamente. Havendo criação do IE, em todos os momentos, pode-se afirmar que ele também é autor dos discursos que circulam em sala de aula. 
"Porque traduzir é co-autorar, o que supõe respeito ao parceiro, o autor, não comentar, explicar ou alterar indevidamente o que este escreveu!" (SOBRAL, 2008, p. 104).

Esperamos, com este estudo, contribuir para as discussões atuais acerca da atuação do intérprete educacional, a partir de um olhar diferenciado para este profissional, que não deve ser posto à sombra de seus interlocutores, mas em evidência - o trabalho de traduzir/interpretar e recriar enunciados é tão árduo quanto o de ensinar e merece discussões mais aprofundadas e que deem destaque a tais práticas.

\section{Notas}

1. A denominação Tradutor e Intérprete de Língua de Sinais (TILS) é utilizada nos textos legais, para referir-se ao profissional competente em tradução e interpretação em Libras e Língua Portuguesa (BRASIL, 2005; BRASIL, 2010), e que pode atuar em diversos espaços sociais. Este artigo tem enfoque nos processos de interpretação, e não de tradução; assim, para referência ao profissional intérprete generalista utilizaremos o termo intérprete de língua de sinais (ILS), e para o profissional que atua em espaços escolares, utilizaremos o termo Intérprete Educacional (IE).

2. Referimo-nos aqui às experiências de inclusão escolar que são comuns às escolas municipais e estaduais na maioria do país em que, normalmente, se conta com a presença de professor regente e IE. Poucas são as experiências em que há presença de professores bilíngues nos anos finais do ensino fundamental, e que podem ministrar suas aulas em Libras.

3. O presente estudo é parte da pesquisa de doutorado desenvolvida pela primeira autora, sob orientação da segunda autora.

4. O termo Oficina, embora remeta à ideia de cursos de curta duração, tinha caráter permanente e visava diferenciar o trabalho do professor em sala de aula. 
5. Justifica-se o uso do termo instrutor surdo pela formação do profissional contratado para a função de ensino de Libras, em nível médio. No período de seleção e contratação de profissionais para atuação no referido Programa não houve candidatos inscritos com formação em nível superior, por esta razão contrataram-se apenas instrutores surdos.

6. Como o Programa não contava com profissionais surdos com formação em nível superior, para ministrar uma disciplina que era parte da grade curricular (em que é necessária tal formação), optou-se por promover a parceria entre professor bilíngue ouvinte e instrutor surdo, a fim de propiciar experiências mais ricas aos alunos ouvintes.

7. É importante destacar que as Oficinas de Libras para professores, funcionários e alunos ouvintes tinham função e objetivos diversos das oferecidas para alunos surdos. Nestes casos tratava-se ensinar Libras àqueles que tinham contato com os surdos presentes na escola, visando tornar a escola bilíngue de fato. O ensino para ouvintes, então, se dava de forma diferente, já que se trata de uma segunda língua.

8. Ainda que a atuação do Intérprete tenha sido videogravada, optamos pela reprodução das imagens pela primeira autora do estudo; embora saibamos das limitações impostas pela reprodução a escolha se deu com o objetivo de preservar a imagem do profissional e garantir seu anonimato.

9. Esclarecemos que, para este estudo, o enfoque era na atuação do intérprete no espaço educacional e suas práticas; neste espaço (e também no referido episódio) as situações de interpretação da Libras para o português oral acontecem com menor frequência, por se tratar de aulas com caráter mais expositivo. Todavia havia momentos em que alunos surdos se manifestavam durante as aulas.

10. Diante da especificidade da Libras quanto à sua materialidade visuogestual, compreendemos que qualquer opção de transcrição apresenta limitações. Entretanto, dada a necessidade de apresentar alguns pontos de tensão relacionados ao objeto desta pesquisa (a atuação do IE), optamos pela transcrição dos enunciados em Libras respeitando sua organização específica, e não pela tradução para o português. Associamos a transcrição, ainda, ao uso de algumas imagens visando maior esclarecimento ao leitor. Dos estudos de Lodi (2004), para a realização da transcrição do português para Libras, assumiu-se:

EM LETRA MAIÚSCULA - enunciados em língua de sinais;

E-N-T-R-E H-Í-F-E-N-S - soletração com alfabeto digital.

Assumiu-se ainda, em apresentações de situações de interrogações, exclamações e afirmações e pausas, o uso de pontuação do português escrito. Quando da utilização 
de duas ou mais palavras em português para expressar um único conceito em Libras, as palavras foram ligadas por hífen (Exemplo: CAVAR-COM-A-MÃO). As demais formas de notação foram escolhas e adaptações das pesquisadoras.

11. Os classificadores na Libras são configurações de mãos que, relacionadas a objetos, pessoas e animais funcionam como marcadores de concordância verbal (BRITO, 1995).

12. Neste artigo apresentamos um recorte da pesquisa de doutorado da primeira autora e, assim sendo, foi possível explorar apenas alguns dos inúmeros aspectos relacionados à complexa atuação do IE.

\section{Referências}

BRASIL. Decreto $N^{o} 3.298$, de 20 de dezembro de 1999. Regulamenta a Lei no 7.853 , de 24 de outubro de 1989, dispõe sobre a Política Nacional para a Integração da Pessoa Portadora de Deficiência, consolida as normas de proteção, e dá outras providências. Diário Oficial da União. Brasília, 21 de dezembro de 1999.

. Decreto $N^{o}$ 5.626. Regulamenta a Lei $\mathrm{n}^{0} 10.436$, de 24 de abril de 2002, que dispõe sobre a Língua Brasileira de Sinais - Libras, e o art. 18 da Lei $\mathrm{n}^{\circ}$ 10.098, de 19 de dezembro de 2000. Diário Oficial da União, Brasília, 22 de dezembro de 2005.

. Lei 10.098 - Acessibilidade. Estabelece normas gerais e critérios básicos para a promoção da acessibilidade das pessoas portadoras de deficiência ou com mobilidade reduzida, e dá outras providências. Publicada no Diário Oficial da União em 19/12/2000.

. Lei 10.436. Dispõe sobre a Língua Brasileira de Sinais - Libras e dá outras providências. Publicada no Diário Oficial da União em 24/04/2002. 
. Lei 12.319. Regulamenta a profissão de Tradutor e Intérprete da Língua Brasileira de Sinais - LIBRAS. Publicada no Diário Oficial da União em 01/09/2010.

. Ministério da Educação e do Desporto. Lei de Diretrizes e Bases da

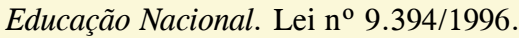

BAKHTIN, M. [1929]. Marxismo e Filosofia da Linguagem. 13 ${ }^{\text {a }}$ ed. São Paulo: Hucitec, 2009.

. Estética da criação verbal. $5^{\text {a }}$. ed. São Paulo: Martins Fontes, 2010.

BELÉM, L.J.M. A atuação do intérprete educacional de Língua Brasileira de Sinais no ensino médio. 2010. 138f. Dissertação (Mestrado em Educação) Universidade Metodista de Piracicaba, Piracicaba, 2010.

BIAGGI, E.L. de C. Cinema e vídeo na obra de Guimarães Rosa: uma análise intersemiótica de "Cara-de-Bronze" e "Famigerado". 2007. Dissertação (Mestrado em Estudos Literários) - Universidade Federal de Minas Gerais, Belo Horizonte, 2007.

BRITO, L.F. Por uma gramática da língua de sinais. Rio de janeiro: Tempo Brasileiro, UFRJ, Departamento de Lingüística e Filologia, 1995.

CAMPOS, H. de. Da tradução como criação e como crítica. In: TÁPIA, M.; NÓBREGA, T.M.(Org.). Haroldo de Campos - Transcriação. 1.ed. São Paulo: Perspectiva, 2013. p. 1-18.

CARR, S. et al. The critical link: Interpreters in the community. Papers from the 1st International Conference on Interpreting in Legal, Health, and Social Service Settings, Geneva Park, Canada, June 1-4, Amsterdam, Philadelphia: John Benjamins Publishing, 1995.

ECO, U. Quase a mesma coisa: experiências de tradução. Trad. Eliana Aguiar. São Paulo: Record, 2007.

FRISHBERG, N. Interpreting: An Introduction. Maryland: RID Publications, 1990. 
GURGEL, T. M. A. O papel do instrutor surdo na promoção da vivência da língua de sinais por crianças surdas. 2004. 90f. Dissertação (Mestrado em Educação) - Universidade Metodista de Piracicaba, Piracicaba, 2004.

KOTAKI, C. S; LACERDA, C.B.F. O intérprete de Libras no contexto da escola inclusiva: focalizando sua atuação na segunda etapa do ensino fundamental. In: LACERDA, C.B,F. de; SANTOS, L.F. dos (Org). Tenho um aluno surdo, $e$ agora? Introdução à Libras e Educação de surdos. São Carlos: EDUFSCar, 2013. p. 201-218.

LACERDA, C. B. F. de; POLETTI, J. E. A escola inclusiva para surdos: a situação singular do intérprete de língua de sinais. In: FÁVERO, O; FERREIRA, W; IRELAND, T; BARREIROS, D. (Org.). Tornar a educação inclusiva. 1. ed. Brasilia: Unesco/ANPED, 2009. p. 159-176, v. 1.

LACERDA, C.B.F.; LODI, A.C. B. A inclusão escolar bilíngue de alunos surdos: princípios, breve histórico e perspectivas. In: LODI, A.C. B e LACERDA, C.B.F.: Uma escola duas línguas: letramento em língua portuguesa e língua de sinais nas etapas iniciais de escolarização. Porto Alegre: Editora Mediação, 2009. p. 11-32.

LACERDA, C.B.F.; SANTOS, L.F dos; CAETANO, J.F. Estratégias metodológicas para o ensino de alunos surdos. In: LACERDA, C.B,F. de; SANTOS, L.F. dos (Org.). Tenho um aluno surdo, e agora? Introdução à Libras e Educação de surdos. São Carlos: EDUFSCar, 2013. P. 185-200.

LODI, A. C. B. A leitura como espaço discursivo de construção de sentidos: oficinas com surdos. 2004. 248f. Tese (Doutorado em Linguística Aplicada e Estudos da Linguagem) - Pontifícia Universidade Católica de São Paulo, São Paulo, 2004.

LODI, A.C.B.; ALMEIDA, E.B.de. Gêneros discursivos da esfera acadêmica e práticas de tradução-interpretação Libras-Português: Reflexões. Tradução \& Comunicação: Revista Brasileira de Tradutores, no. 20, 2010.

MARTINS, V. R. de O. Posição-Mestre: Desdobramentos Foucaultianos sobre a Relação de Ensino do Intérprete de Língua de Sinais Educacional. 2013. 253f. Tese (Doutorado em Educação) Universidade Estadual de Campinas, Campinas, 2013. 
MOURA, M. C. de. A escola bilíngue para surdos: uma realidade possível. In: SÁ, N.R.L. de. (Org.). Surdos: qual escola? Manaus: Editora Valer e Edua, 2011. p. $155-168$.

RODRIGUES, C. H.; MIRANDA, L. A. Fronteiras linguísticas e culturais no processo de ensino aprendizagem: contrapondo as turmas com surdos às de surdos. Anais do SIELP. Volume 2, Número 1. Uberlândia: EDUFU, 2012.

SANTOS, L. F. dos. O instrutor surdo em uma escola inclusiva bilíngue: sua atuação junto aos alunos surdos no espaço da Oficina de Língua Brasileira de Sinais. 2007. Dissertação (Mestrado em Educação) - Universidade Metodista de Piracicaba, Piracicaba, 2007.

SANTOS, S.A. Intérpretes de língua brasileira de sinais: um estudo sobre as identidades. 2006. p. 198. Dissertação (Mestrado em Educação)- Universidade Federal de Santa Catarina, Florianópolis, 2006.

SKLIAR, C. (Org.). Educação \& Exclusão: abordagens socioantropológicas em educação especial. Porto Alegre: mediação, 1997.

SOBRAL, A. U. Dizer o "mesmo" a outros: ensaios sobre tradução. São Paulo: SBS, 2008.

TÁPIA, M.; NÓBREGA, T.M. (Org.). Haroldo de Campos - Transcriação. 1.ed. São Paulo: Perspectiva, 2013.

VASCONCELLOS, M.L. Tradução e interpretação de língua de sinais (TILS) na pós-graduação: a afiliação ao campo disciplinar "Estudos da tradução". Cadernos de Tradução, nº 26, p. 119-144, Florianópolis - 2010/2.

VIGOTSKI, L. S. Pensamento e linguagem. Trad. Jefferson Luiz Camargo. São Paulo: Martins Fontes, $4^{\mathrm{a}}$ ed., 2008.

Recebido em: 30/06/2015 Aceito em: 30/09/2015 